Anaesthesist 2019 - 68 (Suppl 1):S25-S39 https://doi.org/10.1007/s00101-017-0376-3 Published online: 2 November 2017 (c) Springer Medizin Verlag GmbH 2017

CrossMark

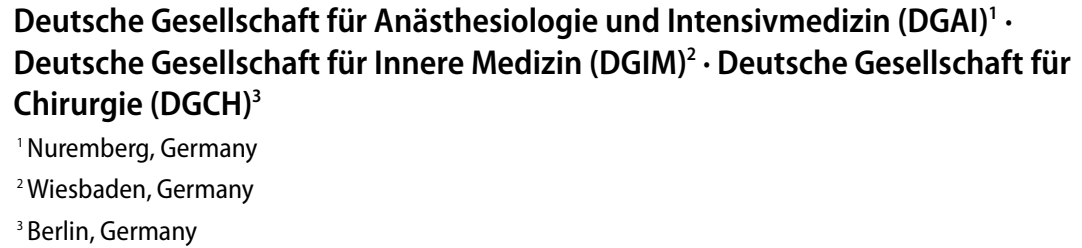

Deutsche Gesellschaft für Anästhesiologie und Intensivmedizin (DGAI) ${ }^{1}$ • Deutsche Gesellschaft für Innere Medizin (DGIM) ${ }^{2}$. Deutsche Gesellschaft für Chirurgie (DGCH) ${ }^{3}$

'Nuremberg, Germany

${ }^{2}$ Wiesbaden, Germany

${ }^{3}$ Berlin, Germany

\title{
Preoperative evaluation of adult patients before elective, noncardiothoracic surgery
}

\author{
Joint recommendation of the German \\ Society of Anesthesiology and Intensive Care \\ Medicine, the German Society of Surgery, \\ and the German Society of Internal Medicine
}

\section{Introduction}

The assessment of a patient's medical history and the physical examination are recognized standards in preoperative evaluation. Whether and under which circumstances technical tests can contribute to reduction of the perioperative risk has not yet been sufficiently investigated. The following recommendations on preoperative evaluation are thus based not only on the available literature, but also on the guidelines of national and international specialist societies, and on expert opinions. The recommendations presented herein are valid for adult patients prior to elective noncardiothoracic surgery. They represent a revised and updated version of the guidelines originally published in 2010 by the German Society of Anesthesiology and Intensive Care Medicine (DGAI), the German Society of Internal Medicine (DGIM), and the German Society of Surgery (DGCH) [1], which have since gained widespread acceptance in German-speaking counties and territories $[2,3]$.

In part $\mathrm{A}$, the general principles of preoperative evaluation are presented. The procedure in patients with known or presumed cardiovascular disease is addressed separately in part B ("Further cardiac testing”). Finally, the perioperative management of long-term medication is discussed (part C).

\section{A general principles}

Preoperative evaluation should take place far enough in advance of the planned surgery, since this enables the length of hospital stay, the number of discontinued surgeries, and also costs to be reduced [4, 5]. Ideally, the appointments for all necessary preoperative evaluations should be scheduled immediately upon establishment of the indication for surgery. However, in general, the interval between preoperative evaluation and surgery should not exceed 6 weeks.

\section{A.1 Medical history and physical examination}

Risk evaluation serves to identify patients with a previously unrecognized or insufficiently managed disease with relevance for the surgery or anesthesia preoperatively, such that treatment can be optimized accordingly. The basis of every preoperative technical test is a thorough medical history including bleeding history 


\begin{tabular}{|l|l|}
\hline $\begin{array}{l}\text { Table } 1 \\
\text { Active cardiac conditions according to [7] }\end{array}$ \\
\begin{tabular}{ll} 
Acute coronary syndrome & Unstable or severe angina (CCS III or IV); recent myocardial infarction ( $>7$ days and $<30$ days) \\
\hline Decompensated heart failure & NYHA IV or worsening of symptoms or new-onset heart failure \\
\hline Significant arrhythmias & $\begin{array}{l}\text { High-grade AV block (Mobitz II, third-degree AV block); } \\
\text { Symptomatic arrhythmia; } \\
\text { Supraventricular arrhythmia (including atrial fibrillation) with a high ventricular pulse rate }>100 / \text { min; } \\
\text { Symptomatic tachycardia; } \\
\text { New ventricular tachycardia }\end{array}$ \\
\hline Relevant valvular disease & $\begin{array}{l}\text { Severe aortic stenosis (gradient }>40 \text { mm Hg, aortic AVA }<1 \mathrm{~cm}^{2} \text { or symptomatic); } \\
\text { Severe mitral stenosis (progressive exercise-induced dyspnea, exercise-induced syncope, or signs of } \\
\text { heart failure) }\end{array}$ \\
\hline CCS Canadian Cardiovascular Society, AVA aortic valve area, NYHA New York Heart Association
\end{tabular} \\
\hline
\end{tabular}

\section{Table 2 Cardiac risk of different interventions [8]}

High risk Aortic surgery/major arterial vascular interventions

Open peripheral artery vascular surgery and amputations of the lower extremities

Thromboembolectomy ${ }^{\mathrm{a}}$

Duodenopancreatectomy

Liver and bile duct surgery

Esophagectomy

Surgery for intestinal perforation ${ }^{\mathrm{a}}$

Adrenal gland removal

Cystectomy (total)

Pneumonectomy

Lung and liver transplantation ${ }^{\mathrm{a}}$

Moderate Intraperitoneal interventions

risk Carotid surgery (patients with neurologic symptoms)

Endovascular aortic surgery

Surgery in the head and neck region

Major neurosurgical, urologic, gynecologic, and orthopedic interventions

Kidney transplantation

Minor intrathoracic interventions

Low risk Superficial interventions

Dental surgery

Thyroid gland surgery

Eye surgery

Plastic reconstructive interventions

Carotid surgery (patients without neurologic symptoms)

Minor urologic (TURP), gynecologic, and orthopedic (knee arthroscopy) surgery

Breast surgery

TURP transurethral resection of the prostate

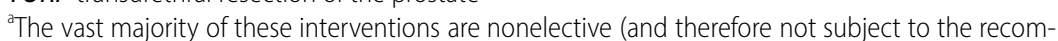
mendations presented herein); they are included here for the sake of completeness

(see A.2.1), an orienting physical examination, and an assessment of the patient's functional capacity. The taking of medical history and the physical examination should follow a standardized scheme.

For more major surgery there is a correlation between malnutrition and postoperative morbidity and mortality. An investigation of nutritional status or a possible food intake disorder using suitable screening instruments, e.g., Nutritional Risk Screening (NRS) 2002, should therefore be included in the preoperative evaluation if malnutrition is suspected (body mass index, BMI, under $18.5 \mathrm{~kg} / \mathrm{m}^{2}$ is a frequent indicator) [6].

If there are no indications of a preexisting disease which could poten-
Table 3 Cardiac risk factors according to

the Revised Cardiac Risk Index (adapted from

$[7,8])$

Heart failure

CHD (angina pectoris and/or status post myocardial infarction)

Cerebrovascular insufficiency (stroke or TIA)

Diabetes mellitus (insulin-dependent)

Renal failure (creatinine $>2 \mathrm{mg} / \mathrm{dl}$ )

Risk factors are assessed on the basis of medical history or clinical records. The probability of serious cardiac complications increases significantly with an increasing number of risk factors $(0.4,0.9,6.6$, and $11 \%$ with $0,1,2$ and 3 or more risk factors, respectively)

CHD coronary heart disease, TIA transient ischemic attack

tially have an impact on perioperative procedures, further tests are not necessary-regardless of the type and duration of surgery and age of the patient.

\section{A.2 Assessment of perioperative risk}

Perioperative complications not of a primarily surgical nature mainly affect the cardiovascular and respiratory systems. It is therefore reasonable to estimate the patient's individual risk of developing such complications preoperatively.

\section{A.2.1 Cardiovascular risk}

The estimation of perioperative cardiac risk and the decision for or against further preoperative diagnostic tests is based primarily on four factors:

a) the presence of an active cardiac condition (- Table 1),

b) the cardiac risk of the surgical intervention (• Table 2), 
Anaesthesist 2019 - 68 (Suppl 1):S25-S39 https://doi.org/10.1007/s00101-017-0376-3

(c) Springer Medizin Verlag GmbH 2017

Deutsche Gesellschaft für Anästhesiologie und Intensivmedizin (DGAI) · Deutsche Gesellschaft für Innere Medizin (DGIM) · Deutsche Gesellschaft für Chirurgie (DGCH)

Preoperative evaluation of adult patients before elective, noncardiothoracic surgery. Joint recommendation of the German Society of Anesthesiology and Intensive Care Medicine, the German Society of Surgery, and the German Society of Internal Medicine

\section{Abstract}

Evaluation of the patient's medical history and a physical examination are the cornerstones of risk assessment prior to elective surgery, and may help to optimize the patient's preoperative medical condition and guide perioperative management. Whether performance of additional technical tests (e. g., blood chemistry, electrocardiography, spirometry, chest $x$-ray) can contribute to reduction of the perioperative risk is often not well known or controversial. Similarly, there is considerable uncertainty among anesthesiologists, internists, and surgeons with respect to perioperative management of the patient's long-term medication. Therefore, the German Scientific Societies of Anesthesiology and Intensive Care Medicine (DGAI), Internal Medicine (DGIM), and Surgery (DGCH) have joined to elaborate recommendations on the preoperative evaluation of adult patients prior to elective noncardiothoracic surgery which were initially published in 2010 . These recommendations have now been updated based on the current literature and existing international guidelines. In the first part, the general principles of preoperative evaluation are described (part $A$ ). The current concepts for extended evaluation of patients with known or suspected major cardiovascular disease are presented in part B. Finally, the perioperative management of patients' longterm medication is discussed (part C). The concepts proposed in these interdisciplinary recommendations endorsed by the DGAI, DGIM, and DGCH provide a common basis for structured preoperative risk assessment and management. These recommendations aim to ensure that surgical patients undergo a rational preoperative assessment and, at the same time, aim to avoid unnecessary, costly, and potentially dangerous testing. The joint recommendations reflect the current state-of-the-art knowledge as well as expert opinions, because scientific-based evidence is not always available. These recommendations will be subject to regular re-evaluation and updating when new validated evidence becomes available.

Contribution available free of charge by "Free Access".

\section{Keywords}

Preoperative evaluation - Perioperative risk . Cardiac risk · Pulmonary risk · Interdisciplinary recommendation

\section{Präoperative Evaluation erwachsener Patienten vor elektiven, nicht Herz-Thorax-chirurgischen Eingriffen. Gemeinsame Empfehlung der Deutschen Gesellschaft für Anästhesiologie und} Intensivmedizin, der Deutschen Gesellschaft für Chirurgie und der Deutschen Gesellschaft für Innere Medizin

\section{Zusammenfassung}

Die präoperative Anamnese und körperliche Untersuchung sind anerkannter Standard bei der Risikoevaluation von Patienten vor elektiven chirurgischen Eingriffen. $\mathrm{Ob}$ und unter welchen Umständen technische Voruntersuchungen dazu beitragen können, das perioperative Risiko zu reduzieren, ist bislang nur unzureichend untersucht. Auch besteht unter Anästhesisten, Chirurgen und Internisten vielfach Unsicherheit im perioperativen Umgang mit der Dauermedikation. Die deutschen wissenschaftlichen Fachgesellschaften für Anästhesiologie und Intensivmedizin (DGAI), Chirurgie (DGCH) und Innere Medizin (DGIM) haben daher eine gemeinsame Empfehlung zur präoperativen Evaluation erwachsener Patienten vor elektiven, nicht Herz-Thorax-chirurgischen
Eingriffen erarbeitet und erstmals im Jahr 2010 publiziert. Die vorliegende Fassung ist eine Überarbeitung der Stellungnahme von 2010 unter Einbeziehung der seither publizierten Literatur sowie von aktuellen Leitlinien internationaler Fachgesellschaften. Zunächst werden die allgemeinen Prinzipien der präoperativen Evaluation dargestellt (Teil A). Das Vorgehen bei Patienten mit bekannten oder vermuteten kardiovaskulären Vorerkrankungen wird gesondert betrachtet (Teil B: „Erweiterte kardiale Diagnostik“). Abschließend wird der perioperative Umgang mit der Dauermedikation diskutiert (Teil C). Die vorgestellten Konzepte stellen fachübergreifende Empfehlungen dar, die ein strukturiertes und gemeinsames Vorgehen ermöglichen sollen. Ihr Ziel ist es, durch transparente und verbindliche Absprachen eine hohe Patientenorientierung unter Vermeidung unnötiger Voruntersuchungen zu gewährleisten, präoperative Untersuchungsabläufe zu verkürzen sowie letztlich Kosten zu reduzieren. Die gemeinsamen Empfehlungen von DGAI, DGCH und DGIM spiegeln den gegenwärtigen Kenntnisstand, aber auch die Meinungen von Experten wider, da nicht für jede Fragestellung wissenschaftliche Evidenz besteht. Daher werden eine regelmäßige Überprüfung und Aktualisierung der Empfehlungen erfolgen, sobald gesicherte neue Erkenntnisse vorliegen.

Schlüsselwörter

Präoperative Evaluation - Perioperatives Risiko · Kardiales Risiko · Pulmonales Risiko 
Table 4 Cardiac risk factors according to the MICA score (Myocardial Infarction and Cardiac

\section{Arrest)}

\section{ASA class}

Risk of the surgery

Age

Renal function (creatinine $>1.5 \mathrm{mg} / \mathrm{dl}$ )

Patient's functional status

Independent

Partially dependent on care

Completely dependent on care

The probability of a perioperative myocardial infarction or cardiac death within 30 days can be calculated based on the abovementioned factors using an internet-based calculator (www.qxmd. com/calculate-online/cardiology/gupta-perioperativecardiac-risk)

ASA American Society of Anesthesiologists

\section{Table 5 Functional capacity}

Adequate functional capacity

$\geq 4$ MET $(>100 \mathrm{~W})$

Poor functional capacity

$<4$ MET $(<100 \mathrm{~W})$

The metabolic equivalent (MET) is used to compare the energy expenditure of different activities. The reference value is the resting metabolic rate of a person (1 MET). For example, a functional capacity of 4 MET means that a person can perform a physical activity that expends 4-times the energy used by the body at rest, e. g., ascend two flights of stairs or perform light housework

Table 6 Predictors of postoperative respiratory failure (adapted from [12])

\begin{tabular}{|c|c|c|}
\hline \multicolumn{2}{|l|}{ Patient-related risk factor(s) } & \multirow{2}{*}{$\begin{array}{l}\text { Risk score } \\
-\end{array}$} \\
\hline Preoperative $\mathrm{SpO}_{2}(\%)$ & $\geq 96$ & \\
\hline & $91-95$ & 7 \\
\hline & $\leq 90$ & 10 \\
\hline $\begin{array}{l}\text { Respiratory symptoms (at } \\
\text { least } 1)^{\mathrm{a}}\end{array}$ & - & 10 \\
\hline \multirow[t]{3}{*}{ Heart failure } & No & - \\
\hline & NYHA I & 3 \\
\hline & NYHA $\geq 2$ & 8 \\
\hline Chronic liver disease & - & 7 \\
\hline \multicolumn{3}{|l|}{ Procedure-related risk factor(s) } \\
\hline Emergency procedure & - & 12 \\
\hline \multirow[t]{4}{*}{ Surgery } & Peripheral & - \\
\hline & $\begin{array}{l}\text { Intrathoracic/upper abdominal } \\
\text { (closed) }\end{array}$ & 3 \\
\hline & Upper abdomen (open) & 7 \\
\hline & Intrathoracic (open) & 12 \\
\hline \multirow[t]{3}{*}{ Duration of surgery (hours) } & $\leq 2$ & - \\
\hline & $2-3$ & 5 \\
\hline & $>3$ & 10 \\
\hline $\begin{array}{l}\text { Risk of postoperative respira- } \\
\text { tory failure }\end{array}$ & Total points (score) & Incidence (\%) \\
\hline Low risk & $<12$ & $1.1(0.7-1.5)$ \\
\hline Moderate risk & $12-22$ & $4.6(3.4-5.6)$ \\
\hline High risk & $\geq 23$ & $18.8(15.8-21.8)$ \\
\hline \multicolumn{3}{|c|}{$\begin{array}{l}\mathrm{SpO}_{2} \text { arterial oxygen saturation determined by pulse oximetry, NYHA New York Heart Association } \\
\text { a Respiratory symptoms: cough and/or sputum at least once a day for } 3 \text { months/year, wheezing (at } \\
\text { any point in the medical history), dyspnea (shortness of breath) upon exertion }\end{array}$} \\
\hline
\end{tabular}

c) the presence of patient-related cardiac risk factors (- Tables 3 and 4), and

d) the patient's functional capacity (- Table 5).

Regarding evaluation of these individual factors, some relevant changes and additions have been made to the content of the joint recommendations published in 2010 [1]. These changes are based in part on the results of the American College of Surgeons National Surgical Quality Improvement Program (ACS NSQIP), which investigated outcomes of more than 450,000 patients in the USA after different interventions [9].

Cardiac risk of the surgery. The proportion of high-risk surgical procedures (previously limited to interventions on the aorta, and iliac and femoral vessels) has increased considerably and nowadays includes, e.g., a range of additional major intraabdominal interventions ( $\bullet$ Table 2 ). On the other hand, endoarterial techniques (e.g., endovascular aneurysm repair, EVAR; previously in the high-risk group) have advantages in terms of the immediate perioperative risk and have now been classified as risk group 2 (moderate risk). Additionally, regarding the perioperative cardiac risk, there is no longer a distinction made between open and laparoscopic interventions.

\section{Patient-related cardiac risk factors/risk}

index. In addition to the risk associated with the surgery itself and the patient's functional capacity, the perioperative risk is determined to a large extent by the patient's preexisting morbidities. Owing to the high relevance of cardiac complications, the Revised Cardiac Risk Index (RCRI) according to Lee continues to be recommended, due to its good validation and the ease of assessment. The current version of the RCRI features five clinical risk factors, for which diabetes mellitus must be insulin dependent and renal failure is characterized more precisely by a stating a creatinine level $>2 \mathrm{mg} / \mathrm{dl}$ (- Table 3; [8]). RCRI is an element of the algorithm for establishing the indication for preoperative electrocardiography (ECG). 
Table 7 Predictors of a postoperative pulmonary complication (adapted from [13])

\begin{tabular}{|l|l|}
$\begin{array}{l}\text { Patient-related risk } \\
\text { factor(s) }\end{array}$ & Risk score \\
\hline ASA $\geq 3$ & 3 \\
\hline $\begin{array}{l}\text { Emergency procedure } \\
\text { High-risk intervention }\end{array}$ & 3 \\
\hline $\begin{array}{l}\text { Heart failure } \\
\text { Chronic pulmonary }\end{array}$ & 2 \\
\hline disease & 1 \\
\hline $\begin{array}{l}\text { Point(s) } \\
\text { Risk of reintu- }\end{array}$ & bation (\%) \\
\hline 0 & 0.12 \\
\hline $1-3$ & 0.45 \\
\hline $4-6$ & 1.64 \\
\hline $7-11$ & 5.86 \\
\hline ASA American Society of Anesthesiologists \\
\hline
\end{tabular}

In addition to the RCRI, the risk index calculated on the basis of ACS NSQIP data, i.e., the so-called MICA score (Myocardial Infarction and Cardiac Arrest), delivers an excellent prediction of cardiac complications (perioperative myocardial infarction or cardiac death within 30 days). Alongside the risk of the surgery (see above) and renal function (creatinine $>1.5 \mathrm{mg} / \mathrm{dl}$ ), other important elements entered into the score are the patient's functional status (independent, partially/completely dependent on care from others), ASA class, and age (•Table 4). The individual risk for a perioperative myocardial infarction can be determined using an interactive calculator (www.qxmd.com/calculateonline/cardiology/gupta-perioperativecardiac-risk). The ACS NSQIP database also allows many other perioperative risks to be calculated (e.g., wound infection).

Functional capacity. Sufficient functional capacity is an excellent predictor of a good perioperative outcome. Additional preoperative tests are thus rarely indicated in patients with good functional capacity. On the other hand, poor functional capacity $(<4$ metabolic equivalents, MET; - Table 5) correlates only relatively weakly with increased perioperative mortality for noncardiac surgery [10]. Additional comorbidities, functional status (independent vs. caredependent), the degree of frailty, and

Table 8 Indications for perioperative blood tests (minimal standard)

(Suspected) organ disease

\begin{tabular}{l|l|l|l|l}
\hline Parameter & Heart/lung & Liver & Kidney & Blood \\
\hline Hemoglobin & + & + & + & + \\
\hline $\begin{array}{l}\text { Leucocytes } \\
\text { Thrombocytes }\end{array}$ & & + & & + \\
\hline $\begin{array}{l}\text { Sodium, Potassium } \\
\text { Creatinine }\end{array}$ & + & + & + & + \\
\hline $\begin{array}{l}\text { ASAT, Bilirubin, } \\
\text { aPTT, and INR }\end{array}$ & + & + & + & + \\
\hline $\begin{array}{l}\text { ASAT aspartate aminotransferase, aPTT activated partial thromboplastin time, INR international } \\
\text { normalized ratio }\end{array}$ & + & & \\
\hline
\end{tabular}

the risk related to the surgery itself are more important prognostic factors here.

\section{A.2.2 Pulmonary risk}

Preoperative evaluation of the lungs and airways is performed with the objective of reducing perioperative pulmonary complications. Alongside medical history and physical examination, technical procedures (chest $\mathrm{x}$-ray, spirometry, blood gas analysis) and specific scoring systems are available $[11,12]$. The risk of postoperative respiratory failure can be estimated on the basis of anamnestic information and the arterial oxygen saturation measured by pulse oximetry (- Table 6; [12]). Moreover, the risk of postoperative respiratory complications can be calculated using a simple score (• Table 7; [13]).

\section{A.3 Further diagnostic tests}

The expanded battery of further diagnostic tests includes blood analyses, 12channel ECG, chest $\mathrm{x}$-ray, lung function tests, Doppler sonography of vessels in the neck and/or legs, and echocardiography. Where ischemic heart disease is suspected, exercise tests and imaging techniques (e.g. coronary angiography) may be indicated.

\section{A.3.1 Blood analyses}

Preoperative laboratory diagnostic tests aim to investigate abnormalities revealed in the medical history and/or physical examination, and determine the severity of the preexisting disease. However, with an increasing number of laboratory parameters, the likelihood of detecting a value which is randomly outside of the normal range also increases (falsepositive result). Furthermore, many studies have shown that laboratory values initially classified as pathologic are frequently not relevant to treatment or don't influence perioperative management. Routine laboratory screening is therefore not recommended [14]. Even the seriousness of the intervention and the age of the patient do not represent scientifically proven indications for preoperative laboratory tests per se.

This also applies to determination of blood coagulation parameters [15]. Conventional coagulation tests (activated partial thromboplastin time, aPTT; international normalized ratio, INR; platelet count) are unable to detect the most frequent coagulopathies (congenital and acquired disorders of platelet function and the von Willebrand factor). Normal values do not, therefore, exclude hemorrhagic diathesis. Coagulation tests are thus only recommended on the basis of a corresponding medication history (e.g., oral vitamin $\mathrm{K}$ antagonists) and where there is clinical suspicion of a coagulopathy, e.g., based on a positive bleeding history as assessed by a standardized questionnaire $[15,16]$.

In patients with known or presumed organ diseases, determination of the blood values of the laboratory parameters presented in $\bullet$ Table $\mathbf{8}$ is recognized as the appropriate minimal standard.

Independently of the presence or absence of organ disease, measurement of hemoglobin concentration is recommended if the planned intervention carries a relevant bleeding risk (e.g., $>10 \%$ ) and could be delayed if necessary. In such instances, causal treatment 


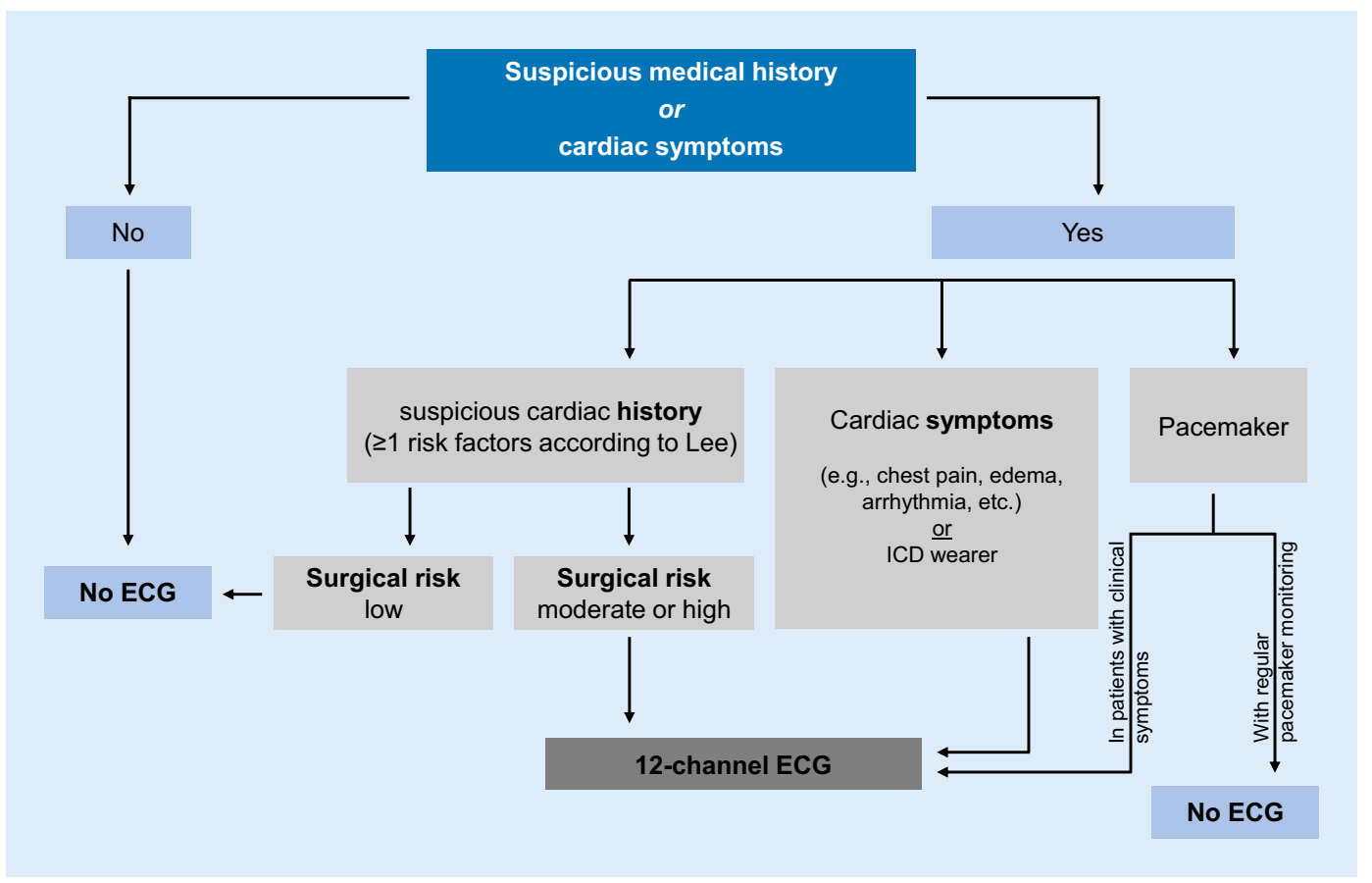

Fig. 1 Recommendations on performing preoperative 12-channel ECG. ECG electrocardiography, ICD implantable cardioverter defibrillator of newly diagnosed anemia (e.g., iron infusions for iron-deficiency anemia) combined with other patient blood management measures would lower the patient's transfusion risk.

Laboratory tests may also be indicated if diagnostic or therapeutic measures which could result in clinically relevant impairment of homeostasis are employed during the preoperative phase $^{1}$. Differentiated preoperative laboratory tests may also be indicated for monitoring potential drug side effects, or in the presence of major organ dysfunction. Diabetes mellitus is a relevant perioperative risk factor and can, despite accurate medical history taking and physical examination, remain undetected preoperatively. However, whether routine preoperative measurement of blood glucose in clinically unremarkable patients can reduce the perioperative risk is unclear. Preoperative measurement of fasting blood glucose is therefore only recommended prior to high-risk interventions (- Table 2), in the presence of additional cardiac risk factors (- Tables 3 and 4), and in overweight pa-

\footnotetext{
1 E. g. measurement of potassium after preoperative colonic irrigation, measurement of creatinine after application of large quantities of contrast agent, etc.
}

tients $\left(\mathrm{BMI}>30 \mathrm{~kg} / \mathrm{m}^{2}\right)$ [17]. In known or newly diagnosed diabetes mellitus, blood glucose levels should be tightly monitored and adjusted perioperatively.

In the absence of founded clinical suspicion, there is no indication for routine preoperative determination of liver-specific laboratory parameters (e.g., gamma glutamyltransferase, $\gamma$-GT; glutamate dehydrogenase, GLDH; aspartate aminotransferase, ASAT; alanine aminotransferase, ALAT; bilirubin). In patients with a history of hepatitis and/or known or suspected alcohol abuse, measurement of transaminases may be considered.

If the medical history indicates possible contagious diseases (e.g., human immunodeficiency virus, HIV; hepatitis $\mathrm{B} / \mathrm{C}$ ), the corresponding diagnostic infection tests are recommended.

Further additional laboratory analyses should only be performed-on an individual basis depending on the findings of the medical history and physical examination-if the results could conceivably influence perioperative procedures. For example, in patients using unfractionated heparin (UFH) for thrombosis prophylaxis, preoperative determination of platelet count (for timely recognition of heparin-induced thrombocytopenia, HIT II) is recommended. However, in patients using low-molecular-weight heparin (LMWH), this is not necessary; in this case, preoperative measurement of creatinine is recommended (due to the risk of over-dosage in renal failure patients) [18].

Patients with preoperatively increased cardiac integrity markers (e. g. troponin; $\mathrm{N}$-terminal pro B-type natriuretic peptide, NT-proBNP) have more perioperative cardiovascular complications [19-21]. Whether routine preoperative measurement of cardiac integrity markers in cardiovascular risk patients can contribute to reducing perioperative morbidity has not yet been clarified and this is thus not recommended. Preoperative measurement with monitoring $48-72 \mathrm{~h}$ postoperatively can, however, be considered for patients with a high cardiac risk $(\mathrm{MET}<4$, RCRI $>1$ for vascular or $>2$ for non-vascular surgery; [8]).

\section{A.3.2 12-channel ECG}

A preoperative 12-channel ECG aims to identify heart diseases which would influence the anesthesia. The following recommendations appear reasonable for establishing the indication (• Fig. 1):

a) In patients with unremarkable medical history and no cardiac symptoms, findings relevant to the anesthesia are rare. In these patients a preoperative 


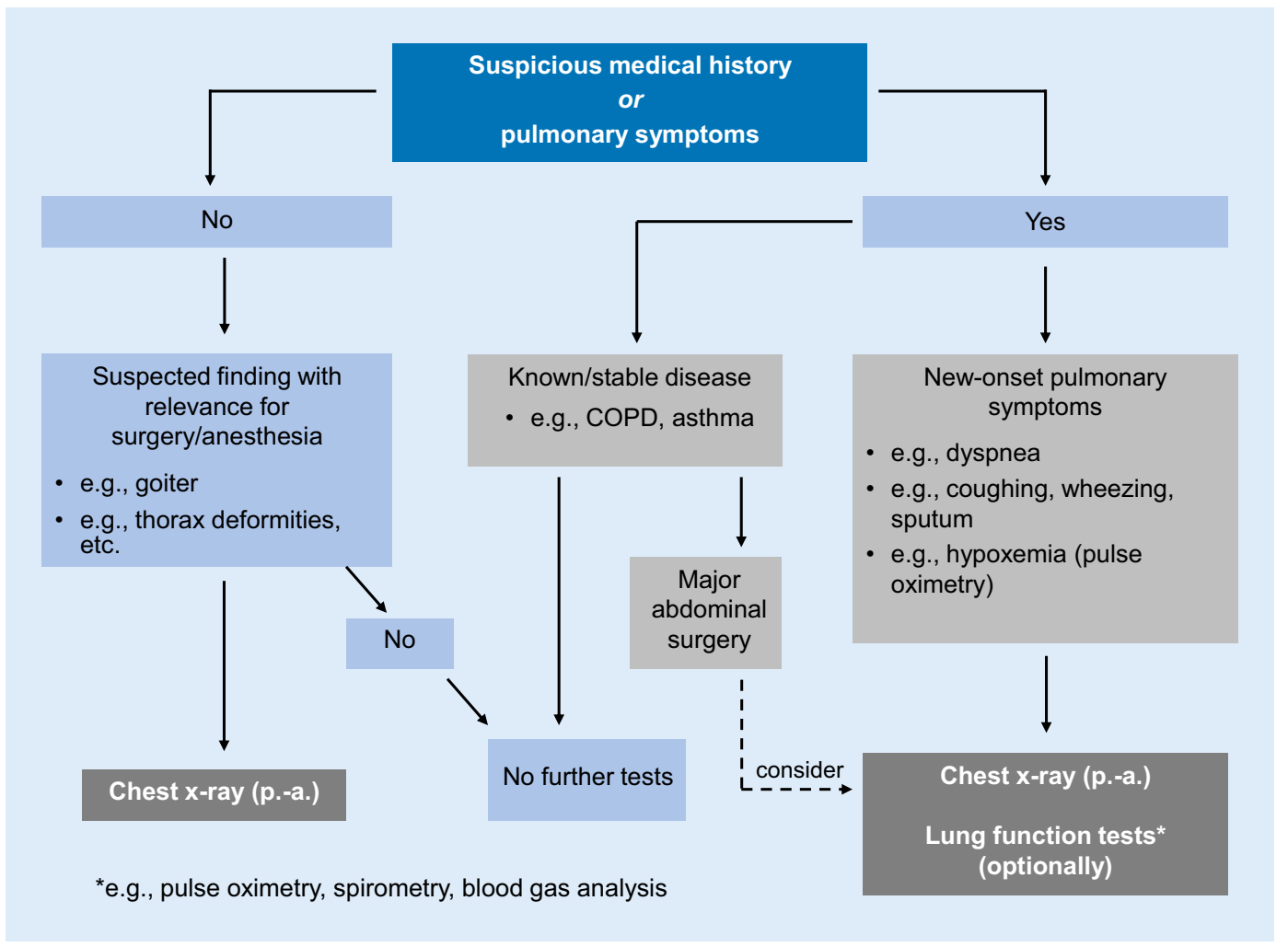

Fig. $2 \triangleleft$ Recommendations on performing preoperative chest $x$-ray (p.-a.) or lung function tests. p.-a. posteroanterior, COPD chronic obstructive pulmonary disease
ECG is not necessary, independent of age [22].

b) In patients without cardiac symptoms, an ECG is recommended prior to surgery with a high or moderate cardiac risk in patients with $\geq 1$ cardiac risk factor (- Table 2; [8])

c) An ECG can be considered in otherwise unremarkable patients $>65$ years prior to moderate-risk surgery, as well as in patients with cardiac risk factors prior to low-risk surgery [8].2.

d) In patients with clinical symptoms of ischemic heart disease, cardiac arrhythmias, valvular disease, heart defects, or (left/right) heart failure, and in patients with an implanted

\footnotetext{
2 The introduction of a 65-year age limit for indication of a preoperative ECG is based on a weak recommendation (level of evidence Ilb, grade of recommendation C) in the ESC/ESA guidelines 2014 [8]. This age limit was not featured in the 2010 DGAI recommendations, is also not found in the guideline from the US societies, and is stated here for the sake of completeness. The usefulness of such an age limit remains, in the authors' opinion, unproven. An age limit is thus not included in the algorithm depictedin • Fig. 1.
}

cardioverter defibrillator (ICD), a preoperative ECG is indicated.

e) In patients with an implanted pacemaker device, a preoperative ECG is unnecessary, provided planned routine pacemaker monitoring appointments have been adhered to and the patient has no clinical symptoms.

\section{A.3.3 Radiologic examination of thoracic organs (chest $x$-ray)}

The sensitivity of a chest $\mathrm{x}$-ray for diagnosis of cardiopulmonary diseases is low in patients with unremarkable medical history and physical examination [23]. Therefore, preoperative chest $\mathrm{x}$-ray is only indicated when a clinical suspicion with consequences for perioperative procedures (e.g., pleural effusion, atelectasis, pneumonia, etc.) is to be confirmed or excluded (• Fig. 2; [24]). Additionally, a thoracic overview x-ray can be helpful in special cases irrespective of cardiopulmonary symptoms (e. g., to assess tracheal displacement in goiter patients). The usefulness of applying fixed age limits to routine performance of chest x-ray has not been scientifically proven.

\section{A.3.4 Lung function tests}

The technical tests available for evaluating lung function are measurement of arterial oxygen saturation via pulse oximetry (at rest/during exercise), spirometry/ spiroergometry, body plethysmography, and arterial blood gas analysis. There is a moderate correlation between the incidence of pathologic findings in lung function tests and the occurrence of perioperative pulmonary complications [11]. Therefore, knowledge of the results of pulmonary examinations can help to reduce perioperative morbidity and mortality not only in patients undergoing thoracic surgery [25], but also in patients with a pulmonary risk undergoing major epigastric interventions [26, 27]. Preoperative lung function tests are thus indicated in patients with new-onset or suspected active pulmonary conditions for estimation of disease severity and treatment monitoring (• Fig. 2). In addition, lung function tests should also be considered in patients with planned major epigastric interventions. 


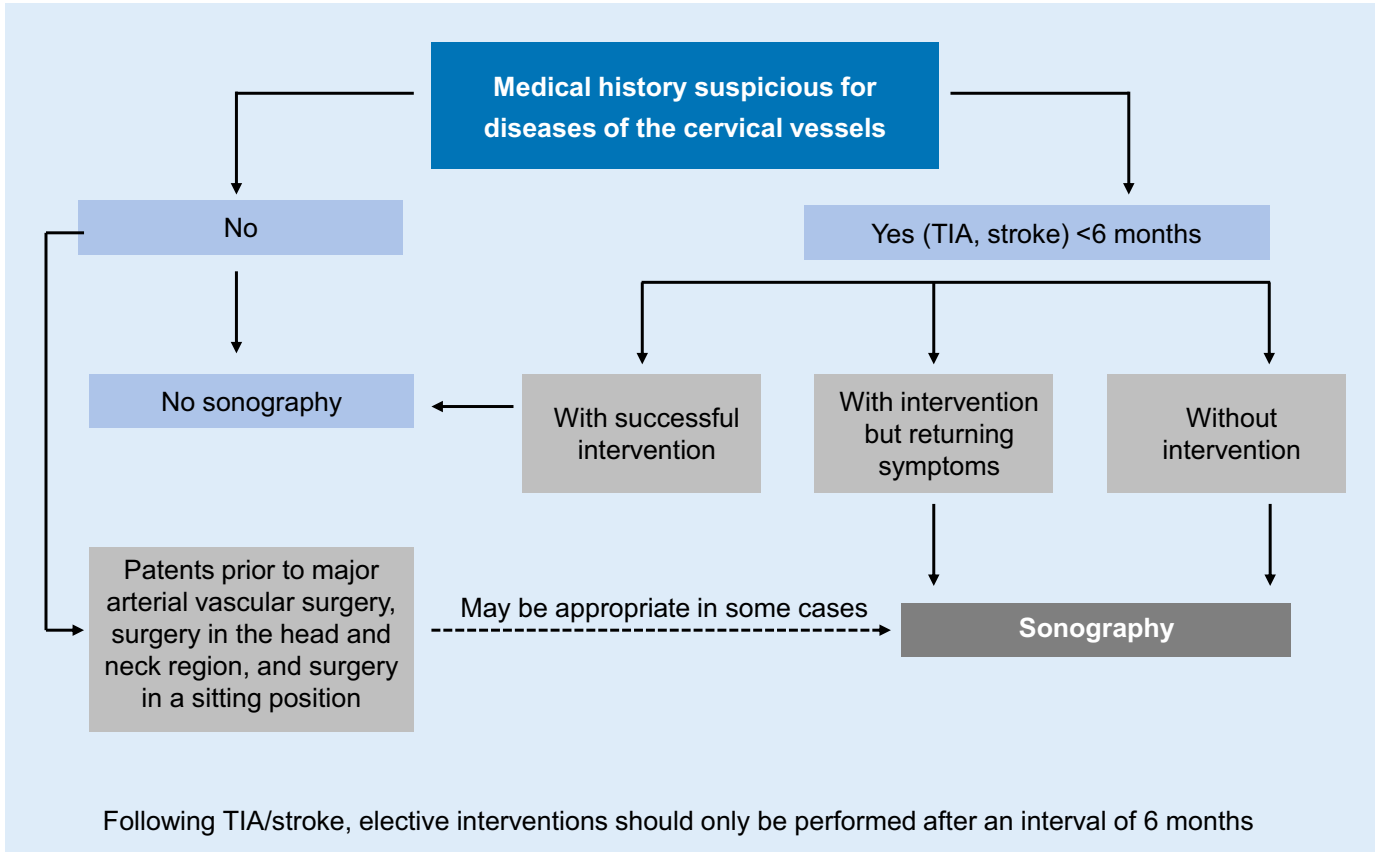

Fig. $3<$ Recommendations on performing preoperative carotid Doppler sonography. TIA transient ischemic attack

\section{A.3.5 (Doppler) echocardiography}

Performed at rest, (Doppler) echocardiography enables direct evaluation of the size, geometry, and function of the heart valves, as well as assessment of intracardiac flow dynamics. The most frequent preoperative indications are:

a) assessment of left and right ventricular pump function, and

b) exclusion of heart and heart valve defects in patients with symptoms of heart failure or pathologic heart murmurs.

Preoperative echocardiography is, however, only recommended prior to noncardiac surgery in patients with newonset dyspnea of unknown origin, and in patients with known heart failure and worsening of symptoms during the previous 12 months. In patients with known, stable heart failure, echocardiography does not contribute to reduction of perioperative risk [28]. Stable heart failure or presumed/proven ischemic heart disease (coronary heart disease, CHD) alone thus does not constitute an indication for preoperative echocardiography. The value of routine preoperative resting-state echocardiography in unremarkable patients prior to high-risk surgery remains unclear [8].
The most frequent preoperatively relevant valve diseases are aortic stenosis and mitral regurgitation. Whether perioperative complications are reduced when patients with a previously unknown or unclarified heart murmur are examined preoperatively by echocardiography is unclear. On the basis of current knowledge, it seems appropriate to consider echocardiography and consult a cardiologist prior to interventions with a moderate or high risk of cardiovascular complications (- Table 2) in patients with previously unknown or unclarified heart murmurs at even normal exercise levels.

\section{A.3.6 Sonography of cervical vessels}

A variety of surgical procedures (e.g. interventions in the head and neck region, cardiothoracic vascular surgery, hip surgery, emergency surgery) are associated with an increased perioperative incidence of apoplectic, generally ischemic insults. Intraoperative hypotension, including position-dependent hypotension (e. g., when the patient is in a half-sitting position), is recognized as an important predisposing factor [29, 30]. Mortality after perioperative insult is twice that after insults occurring outside of the clinic. Established scores for estimation of the perioperative stroke risk are currently not available $[8,29]$. The following procedure appears reasonable on the basis of the available literature (• Fig. $\mathbf{3}$ ):

- The perioperative indications for a diagnostic or therapeutic intervention in the region of the carotid artery do not differ from those in patients not facing surgery [30, 31].

- The interval between a cerebral ischemic attack and elective surgery should be at least 6 months $[8,29]$.

- Preoperative sonography of the carotid artery does not seem to reduce the perioperative stroke risk in patients who have been symptom free for the past 6 months and is therefore not recommended.

- The characteristics of a bruit in the region of the carotid artery do not correlate with the degree of a potentially present stenosis. Definitive recommendations for the preoperative diagnostic workup in patients with a carotid bruit thus do not exist [31]. A target-oriented medical history, particularly a neurologic history, and assessment of vascular risk factors (e.g., peripheral arterial occlusive disease, PAOD) would appear sufficient for risk evaluation in asymptomatic patients with a bruit. 
- Patients who have experienced symptoms indicating carotid artery stenosis within the past 6 months should undergo preoperative diagnostic tests (generally sonography) and, if necessary, treatment $[8,32]$.

Previously symptomatic patients as well as those with prior surgical/interventional treatments generally receive dual antiplatelet therapy, normally for a limited duration. Provided justifiable in terms of the bleeding risk, these prophylactic treatments should not be interrupted perioperatively. In this case, patient management-including the indication to delay surgery-follows the treatment concepts for cardiac patients on dual antiplatelet therapy (see chapter C.6) $[29,31]$.

\section{B Further cardiac testing}

In patients with known or presumed preexistent cardiovascular disease, preoperative cardiac differential diagnostic tests may be necessary. However, due to the often unclear benefit of preoperative cardiologic or cardiosurgical interventions in terms of perioperative morbidity and mortality, strict criteria should be applied when establishing the indication for such tests. Rational evaluation of the perioperative cardiovascular risk as well as the decision for or against extended diagnostic testing is based upon the factors described in section A.2.1.

In patients with an active cardiac condition (e.g. ST elevation myocardial infarction, STEMI), the surgery-with the exception of emergencies-must be delayed, and the cardiac situation clarified and treated preoperatively [7]. This is, in principle, also valid for patients with non-STEMI (NSTEMI); however, in this case the urgency of the surgery must be weighed up against the urgency of the coronary diagnostics and treatment. Upon evidence of relevant myocardial ischemia and significant clinical symptoms (Canadian Cardiovascular Society, CCS, grade III-IV), diagnostic invasive coronary angiography should be performed if drug-based treatment of myocardial ischemia is unsuccessful.
Before elective high-risk surgery, patients with known CHD or a high ischemia risk should be evaluated by a multidisciplinary treatment team comprised of a surgeon, an anesthetist, and cardiologists [8]. The extent of the cardiac risk can contribute to determining the type of intervention.

On the basis of current understanding, performance of noninvasive cardiac stress tests ${ }^{3}$ would only seem appropriate (• Fig. 4)

- in patients with $\geq 3$ clinical risk factors and impaired ( $<4 \mathrm{MET}$ ) or unknown functional capacity prior to high-risk surgery [8]

and can be considered

- in patients with 1-2 clinical risk factors and impaired $(<4$ MET) or unknown functional capacity prior to surgery with a moderate or high cardiac risk [8]. ${ }^{4}$.

There is currently no indication for further cardiac testing

- in patients facing surgery with a low cardiac risk (- Table 2), independent

3 The type and extent of diagnostic testing is determined by the consultant cardiologist. The method currently used most often for ischemia diagnosis is ergometry (exercise ECG). Ergometry enables evaluation of functional capacity, blood pressure, and frequency response, as well as detection of typical ischemic ST segment changes. A capacity of $100 \mathrm{~W}$ corresponds to about 4 MET (- Table 5). The diagnostic value of ergometry is limited when, due to insufficient physical fitness or comorbidities (e. g., arthrosis; PAOD; chronic obstructive pulmonary disease, COPD), no maximum heart rate is reached. Therefore, dobutamine stress echocardiography (DSE) and myocardial scintigraphy are recommended alternatives, particularly in older patients with limited physical capacity. Myocardial scintigraphy is well suited for preoperative prediction of cardiac complications, although its specificity is low. All things considered, DSE is currently viewed as the best diagnostic method for predicting perioperative cardiac events. Ultimately, the selection of the method has to be based on availability and investigator-dependent experiences at the particular location. In the case of positive stress test findings, coronary angiography is generally then performed.

${ }^{4}$ Provided it is expected that the results of corresponding investigations would also influence further perioperative management. of the presence of cardiac risk factors [8]

The indication for invasive coronary diagnostic testing (cardiac catheterization) for estimation of perioperative risk is rare prior to noncardiac surgery. In general, the indication corresponds to that for coronary angiography or percutaneous coronary intervention (PCI) irrespective of the scheduled surgery.

Preoperative coronary angiography is currently only recommended in patients with confirmed myocardial ischemia and in patients with chest pain refractory to pharmacologic treatment, provided the intervention can be postponed [8].

However, in an as-yet unconfirmed study, routine coronary angiography and potential subsequent revascularization in patients with two or more cardiac risk factors prior to major arterial vascular interventions improved perioperative outcome [33]. In another investigation, clinically stable patients (normal ECG, normal echo, no signs of $\mathrm{CHD}$ ) were examined routinely with coronary angiography prior to carotid thromboendarterectomy (TEA) and significant coronary stenosis was found in $31 \%$ [34]. Subsequent revascularization reduced the incidence of severe cardiac complications significantly, from 4.2 to $0 \%$. It is therefore possible that patients facing carotid TEA and patients with a high cardiac risk facing major vascular surgery would benefit from prior invasive diagnostic and therapeutic procedures [8]. There are currently no studies available on the indications for and value of cardiac magnetic resonance imaging (MRI) and cardiac computed tomography (CT) for preoperative evaluation.

\section{Preoperative management of long-term medication}

The assessment of the individual patient's long-term medication is an important part of the preoperative evaluation. The question of whether it is medically justifiable to continue a preoperative drug perioperatively or to initiate a new drugbased treatment prior to surgery has been inadequately investigated. The following recommendations are thus only a guide 


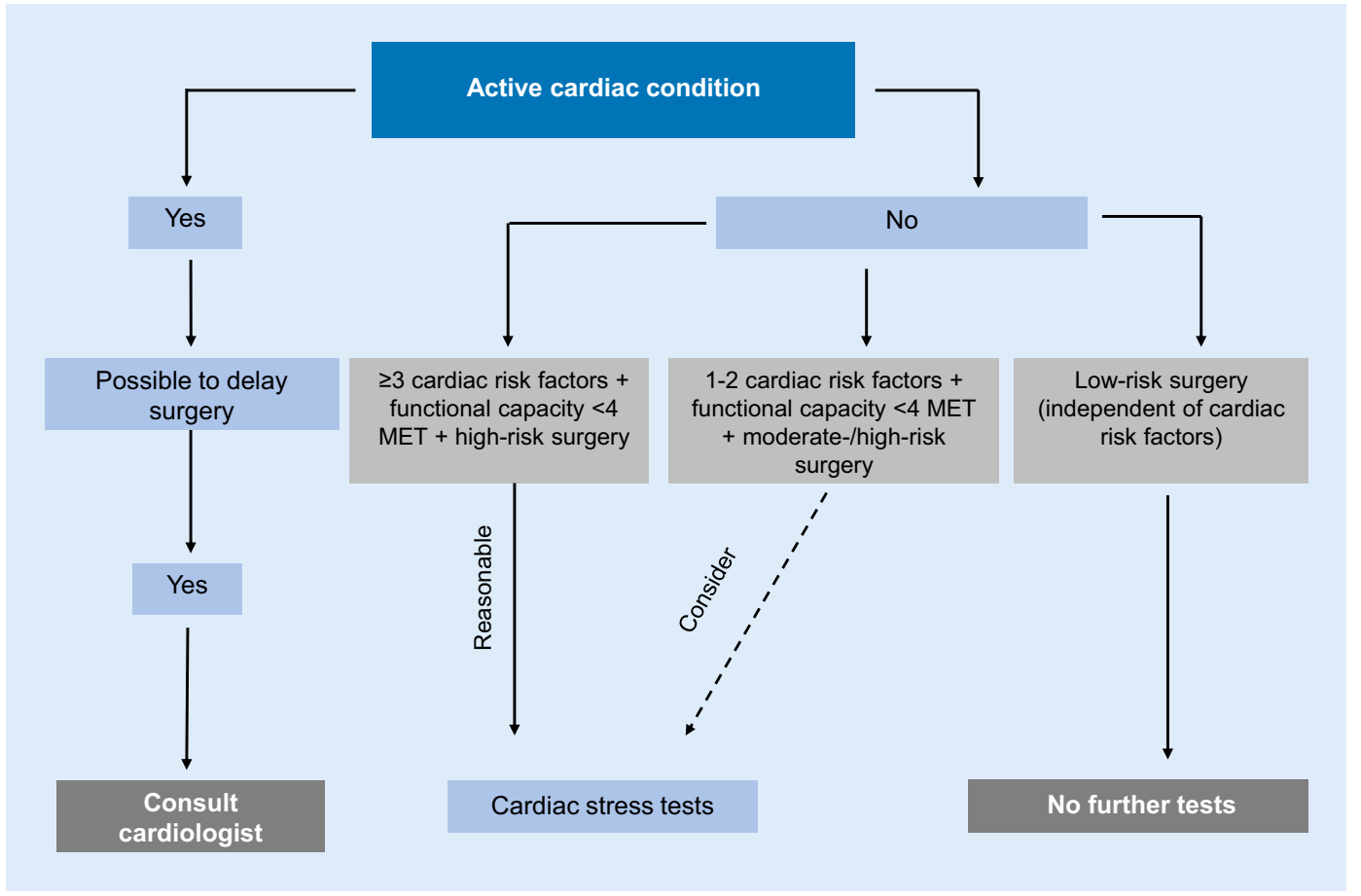

Fig. $4<$ Recommendations on performing preoperative cardiac stress tests (adapted from [8]). MET metabolic equivalent and require critical consideration and potential adaptation on an individual basis.

\section{C.1 Drugs affecting the cardiovascular system}

In the majority of cases, an antianginal, antihypertensive, or antiarrhythmic therapy should be continued. This is particularly true for beta-blockers and nitrate, since discontinuation of these treatments could trigger myocardial ischemia with myocardial infarction.

The indications for preoperative initiation of treatment with beta-blockers are controversially discussed. Preoperative administration of a beta-blocker can be considered

- in all patients with two or more cardiac risk factors according to Lee (RCRI) or ASA class $\geq 3$ who are undergoing surgery with a high cardiac risk,

and

- in all patients with confirmed CHD and documented exercise-induced myocardial ischemia, regardless of the type of intervention [8].

New preoperative titration is not recommended if it cannot be ensured that the beta-blocker dose is accurately titrated according to heart rate and blood pressure far enough in advance of surgery, or when surgery with a low cardiac risk is planned [8].

Whether calcium channel blockers improve perioperative outcome is unclear. In general, preexisting long-term medication should be continued perioperatively. In contrast to this general principle, continued treatment with $d i$ uretics on the day of surgery rarely has advantages, and is associated with a risk of perioperative hypovolemia and hypokalemia. Long-term diuretic treatment should, however, be recommenced rapidly postoperatively, particularly in patients with heart failure [19].

In patients who take angiotensinconverting enzyme inhibitors (ACEI) or angiotensin II receptor blockers (ARB) on the day of surgery, an increased rate of perioperative hypotension is observed. Adequate treatment of this hypotension is often not possible using conventional vasoconstrictors, and vasopressin analogues often have to be applied. Studies have demonstrated a correlation between the extent or duration of perioperative hypotension and the occurrence of postoperative (mainly cardiac) complications. For interventions with large volume shifts and in patients with preexisting or planned sympathicolysis (e.g. beta blockers or peridural anesthesia, PDA), ACEI or ARB medication is usually not taken on the day of surgery. On the other hand, discontinuation of the treatment can lead to perioperative hypertension and, particularly in patients with left ventricular dysfunction, worsen the cardiac situation. Therefore, in patients with preexisting heart failure or left ventricular dysfunction, even a new treatment with ACEI or ARB can be considered a week before surgery [8]. If an ARB is discontinued preoperatively, the medication should be recommenced rapidly postoperatively, since the 30 -day mortality otherwise increases [35].

Due to their low therapeutic index, poor controllability, and arrhythmogenic potency, digitalis glycosides for treatment of chronic heart failure are usually discontinued preoperatively. However, due to the long half-life of such preparations, the benefit of short-term discontinuation is unsure. Patients with atrial fibrillation and a controlled heart rate should continue to receive the medication, since discontinuation can cause perioperative tachycardia. 


\section{C.2 Antidiabetic drugs}

Primarily oral antidiabetic drugs are used to treat type 2 diabetes mellitus. These include sulfonylureas (e. g., glibenclamide), biguanide (metformin), and glinides (e.g. repaglinide), as well as alpha-glucosidase inhibitors (e.g., acarbose), glitazones (e.g., pioglitazon), and gliptins (e.g., sitagliptin). In animal experiments, sulfonylureas prevent ischemia- and volatile anesthesia-induced preconditioning, particularly myocardial preconditioning, and thus enlarge the necrotic area of the myocardium after ischemia. Whether similar effects also occur in humans is unclear; it is therefore also currently unclear whether sulfonylureas should be discontinued preoperatively. Glitazones increase the sensitivity of various tissues to insulin and are used increasingly for glucose management in patients with type 2 diabetes mellitus. There are case studies in the literature describing acute heart failure in connection with glitazones. The relevance of these findings for perioperative management is unclear. The action of gliptins corresponds to the action of the endogenous hormone incretin, and lowers blood glucose via increased insulin release from $\beta$ cells and increased glucagon synthesis in pancreatic $\alpha$ cells. Hypoglycemia generally does not occur with gliptin monotherapy. In rare cases, metformin accumulation (e.g., in patients with renal failure) can lead to lifethreatening lactic acidosis, and a recommendation for its discontinuation $48 \mathrm{~h}$ before the intervention can be found in the prescribing information. However, risk of lactic acidosis during the direct perioperative period appears to be very low [36]. Continuation of metformin medication up until the evening before surgery can thus be justified on the basis of an individual risk-benefit assessment. The British National Health Service (NHS) and the Society of Ambulatory Anaesthesia (SAMBA) even recommend continuation of metformin treatment in patients with healthy kidneys, in part because of results indicating a better outcome with this scheme [37]. However, if application of an intravenous contrast agent is planned, metformin treatment should be paused $24-48 \mathrm{~h}$ in advance of the procedure [38]. Overall, the decision on whether to continue or discontinue oral antidiabetic drugs should be based primarily on blood glucose management and less on potential adverse effects.

Insulins are the standard treatment for type 1 diabetes as well as for advanced-stage type 2 diabetes refractory to oral antidiabetic drugs. Conventional insulin therapy is distinguished from intensive insulin therapy (with a combination of a long-acting basal insulin dose and a short-acting bolus dose at mealtimes) and insulin pump therapy. Preoperative fasting and the postaggression metabolism resulting from the particular type and extent of surgery combine to increase the risk or hypoglycemia if insulin therapy is continued. For short interventions in patients with preoperative intensive insulin therapy, only the basal insulin should be administered on the morning of surgery; the bolus should be omitted. In contrast, in patients with conventional insulin therapy undergoing a short surgical intervention, only $50 \%$ of the normal insulin dose should be applied in a long-acting form. Postoperative insulin therapy can be continued as normal. Tight monitoring and correction of blood sugar is indispensable during the entire perioperative period.

\section{C.3 HMG-CoA reductase inhibitors (statins)}

Lipid-lowering HMG-CoA reductase inhibitors (statins) stabilize vulnerable plaques, have anti-inflammatory effects, inhibit thrombosis formation, and can reduce the incidence of perioperative ischemia, (re)infarction, and mortality in patients with coronary risk [39, 40]. Long-term statin therapy should therefore not be interrupted perioperatively. In vascular surgery patients without previous statin medication, active commencement of prophylaxis at least 2 weeks prior to surgery in recommended [8].

\section{C.4 Vitamin K antagonists}

Anticoagulation therapy with vitamin $\mathrm{K}$ antagonists (usually phenprocoumon) is obligatory in patients with mechanical heart valves and is generally also received by patients with biological heart valves during the first 3 months after implantation. Depending on the type of value and its localization, an international normalized ratio (INR) of 2.0-3.0 should be strived for. Other important clinical indications for vitamin $\mathrm{K}$ antagonists are postthrombotic treatment and atrial fibrillation.

The risk of thromboembolism resulting from perioperative interruption of anticoagulants should be weighed against the perioperative bleeding risk on an individual basis. In instances of discontinuation, treatment is stopped 3-5 days (preferably 5-8 days for phenprocoumon) preoperatively, with daily INR monitoring (target for surgery: <1.5). Preoperative bridging with LMWH, which was long recommended, did not reduce the incidence of arterial thromboembolisms in atrial fibrillation patients, but did increase the risk of major bleeding (from 1.3 to $3.2 \%$ ) [41].

In agreement with this, a prospective registry study also found an increased bleeding rate, a worse cardiac outcome, and increased mortality in patients with bridging [42]. The indication for bridging with LMWH after discontinuing vitamin Kantagonists is thus to be established increasingly critically. Since patients with mechanical heart valves were excluded from the study by Douketis et al. [41], no definitive conclusions can currently be drawn for this patient collective. In patients with a high thromboembolic risk $\left(\mathrm{CHA}_{2} \mathrm{DS}_{2}\right.$-VASc score of 4 or more, mechanical valves, freshly implanted biological heart valves, mitral heart valve reconstruction $<3$ months previously, thrombophilia), bridging with LMWH or UFH is generally still considered to be indicated. The last dose of LMWH should be administered at least $12 \mathrm{~h}$ before surgery (a longer interval is necessary in patients with impaired renal function). The decision for UFH or LMWH for perioperative prophylaxis of venous thromboembolism is not affected by these considerations [18]. 


\begin{tabular}{l|l|l}
\hline \multicolumn{2}{l}{ Table 9} & \multicolumn{2}{l}{ Time required for NOC elimination } & Elimination time \\
\hline Preparation & Target factor & $24-36 \mathrm{~h}$ \\
\hline Rivaroxaban & Xa & $24-36 \mathrm{~h}$ \\
\hline Apixaban & Xa & $24-36 \mathrm{~h}$ \\
\hline Edoxaban & Xa & $24-72 \mathrm{hb}$ \\
\hline Dabigatran & \\
\hline $\begin{array}{l}\text { NOAC novel oral anticoagulant } \\
\text { anhibitor: idarucizumab }\end{array}$ & Ila & \\
bLonger in patients with renal failure & \\
\hline
\end{tabular}

\section{C.5 Direct oral anticoagulants (DOAC)}

The acronyms NOAC (novel oral anticoagulants) and DOAC (directly acting oral anticoagulants) are used synonymously for a group of orally/enterally administered factor IIa or factor Xa inhibitors which have been available for 5-10 years (NOAK "neue orale Antikoagulanzien" is also used in the German-language literature). The current indications are prophylaxis of stroke and systemic embolisms in non-valvular atrial fibrillation, treatment and secondary prophylaxis of deep vein thrombosis and lung embolisms, and thromboembolic prophylaxis in patients with elective hip and knee joint surgery.

NOACs (half-life 9-14h) are eliminated via a number of routes (with the exception of dabigatran, which is eliminated primarily via the kidneys). In the context of elective surgery in adults with a moderate bleeding risk, the minimum elimination time intervals stated in the following section (corresponding to at least 2-3 half-lives [8]) should be observed before surgery after discontinuation of the corresponding substance (- Table 9; [43, 44]).

The time interval to be waited before surgery depends on renal function. In clinical routine, $48 \mathrm{~h}$ represents a safe interval, except for the situation of dabigatran application in patients with renal failure. In emergency situations, application of 25-50 IU/kg body mass prothrombin complex concentrate (PCC) can be considered. Idarucizumab is an available dabigatran antidote, whereas an antidote to factor Xa inhibitors is currently under clinical investigation.

Whether a NOAC should remain unchanged preoperatively, be discontinued long enough in advance of surgery (in dependence of the elimination time; premature discontinuation must be avoided), or be exchanged for heparin depends on the type of surgery and the associated bleeding risk, as well as the original indication for anticoagulant therapy. The decision should be made in close collaboration between the involved specialist disciplines (usually surgery, anesthesia, and internal medicine).

Postoperatively, anticoagulation therapy should be recommenced as soon as possible, although the current bleeding risk must be taken into consideration. In patients with atrial fibrillation or thrombosis/embolism, it may be necessary to bridge several postoperative days with heparin (LMWH or NMH) or fondaparinux, until a switch back to NOAC is possible. In contrast to the procedure with vitamin $\mathrm{K}$ antagonists, the switch back to NOAC is made without overlapping, i.e., the first tablet is taken $12 \mathrm{~h}$ after LMWH or fondaparinux.

Specific requirements covering the handling of NOACs (and platelet aggregation inhibitors) exist for spinal anesthesia, and these should be observed [45].

\section{C.6 Platelet aggregation inhibitors}

Patients with CHD generally receive long-term medication with aspirin and often also with a P2Y12 inhibitor (e.g., clopidogrel). For patients after surgical or interventional coronary revascularization (e.g., stenting), but also for patients with acute coronary syndrome, the benefit of temporary (see below) dual antiplatelet therapy has been proven. In these high-risk patients, the perioperative bleeding risk is outweighed by the risk of myocardial infarction as a con- sequence of medication discontinuation (reviewed in [46]).

Therefore, on the basis of current understanding, only before major surgery associated with a high bleeding risk should $\mathrm{P}_{2} \mathrm{Y}_{12}$ inhibitors be stopped 5 (clopidogrel/ticagrelor) or 7 days (prasugrel) preoperatively. In patients with a high risk of an ischemic myocardial event after stent implantation, this decision must be made in consultation with the treating cardiologist on an individual basis. Discontinuation is mandatory prior to interventions in sealed cavities (posterior chamber of the eye, intraspinal and intracerebral interventions) as well as before regional spinal anesthesia. Perioperative management of aspirin therapy also proceeds on an individual basis. In patients with a high coronary risk (recurrent angina pectoris; status after acute coronary syndrome; status after coronary intervention with a bare metal stent, BMS, or a drug eluting stent, DES), aspirin medication (e.g., $100 \mathrm{mg} /$ day) should only be interrupted perioperatively in the presence of absolute contraindications (e.g., neurosurgical intervention; review in [46]).

Due to the nature of the intervention, patients after isolated PCI or stent implantation have a vulnerable, highly thrombogenic vascular system. Therefore, CHD patients currently receive lifelong aspirin treatment (75-162 mg). Following implantation of a BMS in patients with stable $\mathrm{CHD}$, additional $\mathrm{P} 2 \mathrm{Y}_{12}$ inhibition with clopidogrel ( $75 \mathrm{mg} /$ day) for at least 4 weeks is necessary. Following DES implantation, the duration of obligatory dual antiplatelet therapy increased to 6 (new-generation DES) or 12 months (DES of the older generation) [8]. In patients with balloon angioplasty without stent implantation, dual antiplatelet therapy with clopidogrel is recommended for 2-4 weeks (- Fig. 5; [47, 48]).

Regardless of the type of stent implanted, after acute coronary syndrome (ACS) all patients must receive dual antiplatelet therapy with aspirin plus ticagrelor or prasugrel (in individual patients with a high bleeding risk clopidogrel may also be considered). Pausing $\mathrm{P}_{2} \mathrm{Y}_{12}$ inhibition during the first 12 months in 


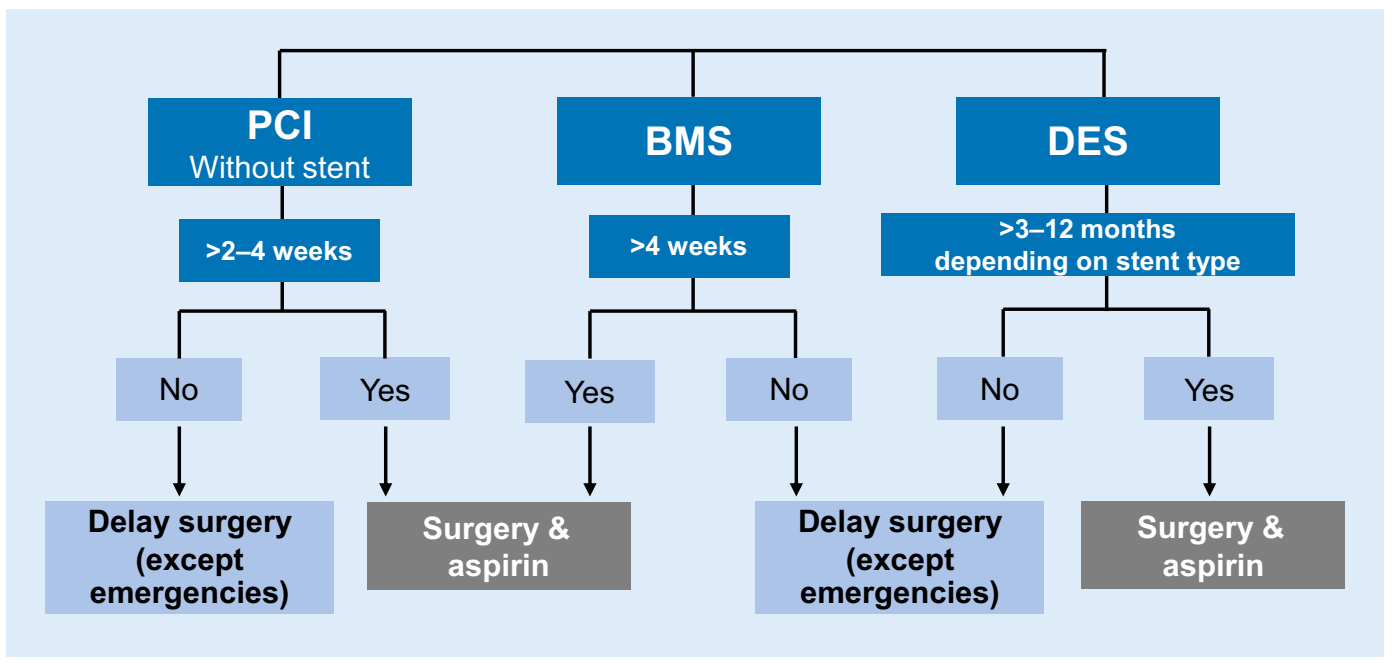

Fig. $5<$ Recommendations on temporal management of elective surgery in patients with coronary stents in dependence of stent type and time of implantation (adapted from $[8,47,48]$ ) $P C l$ percutaneous coronary intervention, $B M S$ bare metal stent, DES drug eluting stent patients with ACS must be discussed on an individual basis.

Surgical interventions during the first weeks after a coronary intervention are particularly prone to complications and associated with high mortality. It is, however, currently unclear how long the interval between stent implantation and surgery should be to ensure optimal patient safety. The 2014 ESC/ESA guideline suggests waiting at least 14 days before performing elective interventions after PCI without stent implantation, at least 4 weeks (better 3 months) after implantation of a BMS, and at least 3-12 months after implanting a DES, depending on the type of DES (first, second, third generation; [8]; • Fig. 5).

\section{C.7 Psychotropic drugs}

The long-term medication of patients with psychoses or neurologic diseases is generally not interrupted. However, some psychopharmaceuticals have drug interactions that should be considered perioperatively.

Tricyclic antidepressants (TCAs) inhibit reuptake of dopamine, noradrenaline, and serotonin in the central nervous system (CNS) and peripheral tissues. Chronic TCA application promotes emptying of central catecholamine stores and increases adrenergic tone. The effect of direct sympathomimetic drugs is increased in patients with long-term TCA therapy, whereas the effect of indirect sympathomimetic drugs is attenuated. This is particularly important where local anesthesia supplemented with epinephrine is used. TCAs also increase the effect of hypnotic drugs, opioids, and inhaled anesthesia.

Serotonin reuptake inhibitors (SSRI) inhibit presynaptic reuptake of serotonin in the synaptic cleft. Preoperative discontinuation of SSRI can cause withdrawal symptoms. On the other hand, SSRI simultaneous with administration of other drugs that inhibit serotonin reuptake or have serotomimetic effects (e.g. pethidine; pentazocine; tramadol; monoamine oxidase, MAO, inhibitors) can cause serotonin syndrome, with hyperthermia, vegetative instability, and disorders of consciousness including coma.

Monoamine oxidase (MAO) inhibitors are subclassified into three groups: firstgeneration substances (isocarboxazid, tranylcypromine, phenelzine) have nonselective and irreversible activity against MAO A and MAO B; agents of the second generation have selective and irreversible activity (clorgyline against MAO A and deprenyl against MAO B); third-generation agents have selective and reversible activity (moclobemide against MAO A, RO-19-6327 against MAO B). MAO inhibitors can interact with drugs administered in the perioperative period. Difficult-to-control hypertensive crises resulting from noradrenaline release in patients with indirect sympathomimetic drugs have been described. Similarly serious is the excitatory reaction after application of pethidine, tramadol, and dextromethorphan, which is characterized by excessive serotonergic activity.

The severity of these events led to obligatory discontinuation of MAO inhibitors before elective surgery in the past. This was particularly valid for the irreversible and nonselective MAO inhibitors. The MAO recovery time is about 2 weeks. Not only could discontinuation result in a dangerous relapse for the patient in terms of their underlying psychiatric disease, but it is also not possible to observe this interval in emergency situations. By adhering to the absolute contraindications for pethidine and tramadol, as well as by avoiding hypoxemia, hypercarbia, arterial hypertension, and the use of indirect sympathomimetic drugs (epinephrine), preoperative discontinuation of $\mathrm{MAO}$ inhibitors is no longer considered necessary. Since reversible and selective MAO inhibitors are now available, for the 2-week period preceding planned interventions, irreversible MAO inhibitors should be exchanged for reversible inhibitors, which have a duration of action of only $24 \mathrm{~h}$. There are currently no case studies in the literature describing perioperative complications in patients with reversible MAO inhibitors.

Lithium is used primarily to treat bipolar affective disorders. Due to its narrow therapeutic index and metabolism similar to that of sodium, tight perioperative monitoring of lithium concentration is recommended. Alternatively, perioperative discontinuation $72 \mathrm{~h}$ before surgery is under discussion, predominantly be- 
cause no withdrawal symptoms are to be expected; however, the risk of intoxication in the instance of perioperative hemodynamic instability or impaired renal function (lithium is excreted via the kidneys) is high. Treatment should be recommenced rapidly postoperatively in a stable electrolyte situation.

Neuroleptic agents are a highly heterogeneous group of psychotropic drugs with sedative and antipsychotic properties. They are mainly used to treat delusions and hallucinations in patients with schizophrenia and bipolar disorders. Owing to the risk of psychotic episodes returning and on the basis of an increased rate of postoperative confusion, neuroleptic agents should be continued perioperatively.

Antiepileptic drugs should be continued perioperatively. The requirement for opioids and relaxants may be increased in these patients.

Methylphenidate is an amphetamine derivative used to treat attention deficit hyperactivity disorder (ADHD) and narcolepsy. Methylphenidate can increase anesthetic requirements. Due to its short half-life $(2-4 \mathrm{~h}$ in unretarded, up to $12 \mathrm{~h}$ in retarded tablet form), methylphenidate can be continued up to premedication.

\section{C.8 Antiparkinson medication}

The symptoms experienced by Parkinson disease patients are caused by dopamine deficit in the region of the substantia nigra. Long-term therapy in Parkinson patients thus primarily comprises substances which increase the concentration or effect of dopamine in the brain, e.g. via exogenous supply of dopamine (L-DOPA) and dopamine agonists (e.g. bromocriptine), by slowing the degradation of endogenous dopamine via MAO B inhibitors (e.g. selegiline), or by increasing dopamine release via N-methyl D-aspartate (NMDA) receptor antagonists (e.g. amantadine). The effect of L-DOPA monotherapy is superior to that of all other antiparkinson medications, and this is therefore the most common treatment. The half-life of L-DOPA is short and a 6-12-hour interruption of therapy can cause severe muscle rigidity or a Parkinson crisis with life-threatening symptoms such as dysphagia and respiratory dysfunction. Therefore, oral medication with L-DOPA and also with all other antiparkinson medications should be continued until the morning of surgery and recommenced immediately postoperatively. In cases where oral medication is not possible postoperatively, the possibility of preoperative conversion to a transdermally absorbable dopamine agonist (e.g. rotigotine plaster) should be discussed with a neurologist.

Dopamine antagonists (e.g. metoclopramide) and medications associated with a risk of extrapyramidal symptoms (e. g. droperidol $\mathrm{HT}_{3}$ antagonists) should be avoided. In the case of an akinetic Parkinson crisis titrated intravenous application of amantadine (e. g. 1-2-times $200 \mathrm{mg}$ i. v. over $3 \mathrm{~h}$ is recommended).

\section{C.9 Corticosteroids}

Independent of dose (above or below the Cushing's threshold) and method of application (systemic or topical), patients with long-term steroid medication ( $>5$ days) are at risk of inadequate cortisol production [49]. Case studies indicate a correlation between cortisol deficiency and intraoperative hypotension or shock, although this has not yet been unequivocally proven $[49,50]$. Therefore, in general, patients should not interrupt their long-term steroid medication in the perioperative phase and take this as normal on the morning of surgery.

It is unclear whether patients with long-term steroid medication below the Cushing's threshold benefit from additional perioperative steroid administration [51]. Due to the individual and highly variable reactions to surgical trauma, as well as differing suppression of endogenous cortisol synthesis by exogenous steroids, the following procedure can be considered on the basis of expert opinion:

- Minor surgery (e.g. endoscopic surgery, herniotomy, thyroid gland removal) $\rightarrow$ application of $25 \mathrm{mg}$ hydrocortisone at the start of surgery.

- Medium-sized surgery (e. g., abdominal surgery) $\rightarrow$ application of $100 \mathrm{mg}$ hydrocortisone over $24 \mathrm{~h}$, recommencement of normal steroid medication the next day.

- Major surgery with a risk of postoperative systemic inflammatory response syndrome (SIRS) $\rightarrow$ application of $100 \mathrm{mg}$ hydrocortisone over $24 \mathrm{~h}$ (e. g. $4 \mathrm{mg} / \mathrm{h}$ ) on the day of surgery, $50 \mathrm{mg}$ over $24 \mathrm{~h}$ the day after surgery, and $25 \mathrm{mg}$ hydrocortisone on the second postoperative day (also possible orally).

\section{Conclusion}

The concepts presented herein for preoperative evaluation of adult patients prior to elective noncardiothoracic surgery represent multidisciplinary recommendations that enable structured and concerted patient management, and should improve the quality of treatment. Through transparent and binding agreements, these recommendations aim to ensure highly patient-oriented clinical management with avoidance of unnecessary preoperative tests, thus reducing preoperative examination times and, ultimately, costs. A corollary of this is that for some individual patients, individual concepts have to be generated.

The presented joint recommendations from the DGAI, DGCH, and DGIM reflect the current state of knowledge but also expert opinions, since scientific evidence does not exist for every scenario. Therefore, these guidelines will be regularly reviewed and updated as soon as new findings become available.

\section{Corresponding address}

Prof. Dr. B. Zwissler

Department of Anesthesiology, University Hospital, LMU Munich

Marchioninistr. 15, 81377 Munich, Germany

Bernhard.Zwissler@med.uni-muenchen.de

\section{Compliance with ethical guidelines}

Conflict of interest. G. Geldner, J. Karst, F. Wappler, B. Zwissler, P. Kalbe, U. Obertacke, and M. Pauschinger declare that they have no competing interests. W. Schwenk receives consulting fees from Bayer for a decision tool for perioperative use of NOACs, but abstained from voting on the corresponding passages. 
This article does not contain any studies with human participants or animals performed by any of the authors

\section{References}

1. Deutsche Gesellschaft für Anästhesiologie und Intensivmedizin, - (2010) Preoperative evaluation of adult patients prior to elective, non-cardiac surgery: joint recommendations of German Society of Anesthesiology and Intensive Care Medicine, German Society of Surgery and German Society of Internal Medicine. Anaesthesist 59(11):1041-1050

2. Böhmer AB etal (2014) Preoperative riskevaluation of adult patients prior to elective non-cardiac surgery: follow-up survey of the recommendations published in 2010. Anaesthesist 63(3):198-208

3. Böhmer AB etal (2012) Preoperative riskevaluation of adult patients for elective, noncardiac surgical interventions. Results of an on-line survey on the status in Germany. Anaesthesist 61(5):407-419

4. Wijeysundera DN et al (2009) A populationbased study of anesthesia consultation before major noncardiac surgery. Arch Intern Med 169(6):595-602

5. Ferschl MB et al (2005) Preoperative clinic visits reduce operating room cancellations and delays. Anesthesiology 103(4):855-859

6. Weimann A etal (2014) Clinical nutrition in surgery Guidelines of the German Society for Nutritional Medicine. Chirurg 85(4):320-326

7. Fleisher LA et al (2007) ACC/AHA 2007 Guidelines on perioperative cardiovascular evaluation and care for noncardiac surgery: executive summary: a report of the American College of Cardiology/ American Heart Association Task Force on Practice Guidelines. Circulation 116(17):1971-1996

8. Kristensen SD et al (2014) 2014ESC/ESA Guidelines on non-cardiac surgery: cardiovascular assessment and management: The Joint Task Force on non-cardiac surgery: cardiovascular assessment and management of the European Society of Cardiology (ESC) and the European Society of Anaesthesiology (ESA). Eur J Anaesthesiol 31(10):517-573

9. Gupta PKet al (2011) Development and validation of a risk calculator for prediction of cardiac risk after surgery. Circulation 124(4):381-387

10. Wiklund RA, Stein HD, Rosenbaum SH (2001) Activities of daily living and cardiovascular complications following elective, noncardiac surgery. Yale J Biol Med 74(2):75-87

11. Canet J et al (2010) Prediction of postoperative pulmonary complications in a population-based surgical cohort. Anesthesiology 113(6):1338-1350

12. Canet J et al (2015) Development and validation of a score to predict postoperative respiratory failure in a multicentre European cohort: a prospective, observational study. Eur J Anaesthesiol 32(7):458-470

13. Brueckmann B et al (2013) Development and validation of a score for prediction of postoperative respiratory complications. Anesthesiology 118(6):1276-1285

14. Smetana GW, Macpherson DS (2003) The case against routine preoperative laboratory testing Med Clin North Am 87(1):7-40

15. Chee YL et al (2008) Guidelines on the assessment of bleeding risk prior to surgery or invasive procedures. British Committee for Standards in Haematology. Br JHaematol 140(5):496-504
16. Pfanner G et al (2007) Preoperative evaluation of the bleeding history. Recommendations of the working group on perioperative coagulation of the Austrian Society for Anaesthesia, Resuscitation and Intensive Care. Anaesthesist 56(6):604-611

17. Kerner W, Brückel J (2008) Definition, Klassifikation und Diagnostik des Diabetes mellitus. Diabetol Stoffwechs 3(Suppl 2):131-133

18. S3-Leitlinie Prophylaxe der venösen Thromboembolie (VTE). 2015: http://www.awmf. org/uploads/tx_szleitlinien/003-001I_S3_VTEProphylaxa:2015-12.pdf. Zugegriffen: 12.05.2017

19. Poldermans D et al (2009) Guidelines for pre-operative cardiac risk assessment and perioperative cardiac management in non-cardiac surgery. Eur Heart J30(22):2769-2812

20. Choi JH et al (2010) Preoperative NT-proBNP and CRP predict perioperative major cardiovascular events in non-cardiac surgery. Heart 96(1):56-62

21. Potgieter D et al (2015) N-terminal pro-B-type natriuretic peptides' prognostic utility is overestimated in meta-analyses using study-specific optimal diagnostic thresholds. Anesthesiology 123(2):264-271

22. Liu LL, Dzankic S, Leung JM (2002) Preoperative electrocardiogram abnormalities do not predict postoperative cardiac complications in geriatric surgical patients. J Am Geriatr Soc 50(7):1186-1191

23. Fritsch Getal (2012) Abnormal pre-operative tests, pathologic findings of medical history, and their predictive value for perioperative complications. Acta Anaesthesiol Scand 56(3):339-350

24. Feely MA et al (2013) Preoperative testing before noncardiac surgery: guidelines and recommenda tions. Am Fam Physician 87(6):414-418

25. Arozullah AM, Conde MV, Lawrence VA (2003) Preoperative evaluation for postoperative pulmonary complications. Med Clin North Am 87(1):153-173

26. Ohrlander T, Dencker M, Acosta S (2012) Preoperative spirometry results as a determinant for long-term mortality after EVAR for AAA. Eur J Vasc Endovasc Surg 43(1):43-47

27. Jeong O, Ryu SY, Park YK (2013) The value of preoperative lung spirometry test for predicting the operative risk in patients undergoing gastric cancer surgery. J Korean Surg Soc 84(1):18-26

28. Halm EA et al (1996) Echocardiography for assessing cardiacriskin patients having noncardiac surgery. Study of Perioperative Ischemia Research Group. Ann Intern Med 125(6):433-441

29. Jorgensen ME et al (2014) Time elapsed after ischemic stroke and risk of adverse cardiovascular events and mortality following elective noncardiac surgery. JAMA 312(3):269-277

30. Mashour GA, Woodrum DT, Avidan MS (2015) Neurological complications of surgery and anaesthesia. Br J Anaesth 114(2):194-203

31. Mashour GA et al (2014) Perioperative care of patients at high risk for stroke during or after non-cardiac, non-neurologic surgery: consensus statement from the Society for Neuroscience in Anesthesiology and Critical Care. J Neurosurg Anesthesiol 26(4):273-285

32. De Hert $\mathrm{S}$ et al (2011) Preoperative evaluation of the adult patient undergoing non-cardiac surgery: guidelines from the European Society of Anaesthesiology. Eur J Anaesthesiol 28(10):684-722

33. Monaco $M$ et al (2009) Systematic strategy of prophylactic coronary angiography improves long-term outcome after major vascular surgery in medium- to high-risk patients: a prospective, randomized study. J Am Coll Cardiol 54(11):989-996
34. Illuminati G et al (2010) Systematic preoperative coronary angiography and stenting improves postoperative results of carotid endarterectomy in patients with asymptomatic coronary artery disease: a randomised controlled trial. Eur J Vasc Endovasc Surg 39(2):139-145

35. LeeSM, TakemotoS, Wallace AW (2015)Association between withholding angiotensin receptor blockers in the early postoperative period and 30-day mortality: a cohort study of the Veterans Affairs Healthcare System. Anesthesiology 123(2):288-306

36. Duncan Al et al (2007) Recent metformin ingestion does not increase in-hospital morbidity or mortality after cardiac surgery. Anesth Analg 104(1):42-50

37. Aldam P, Levy N, Hall GM (2014) Perioperative management of diabetic patients: new controversies. Br J Anaesth 113(6):906-909

38. Joshi GP et al (2010) Society for Ambulatory Anesthesia consensus statement on perioperative blood glucose management in diabetic patients undergoing ambulatory surgery. Anesth Analg 111(6):1378-1387

39. Schouten $O$ et al (2009) Fluvastatin and perioperative events in patients undergoing vascular surgery. N Engl J Med 361(10):980-989

40. Berwanger $O$ et al (2016) Association between pre-operative statin use and major cardiovascular complications among patients undergoing noncardiac surgery: the VISION study. Eur Heart J 37(2):177-185

41. Douketis JD et al (2015) Perioperative bridging anticoagulation in patients with atrial fibrillation. NEngl J Med 373(9):823-833

42. Steinberg BA et al (2015) Use and outcomes associated with bridging during anticoagulation interruptions in patients with atrial fibrillation: findings from the Outcomes Registry for Better Informed Treatment of Atrial Fibrillation (ORBITAF). Circulation 131(5):488-494

43. Kovacs RJ et al (2015) Practical management of anticoagulation in patients with atrial fibrillation. JAm Coll Cardiol 65(13):1340-1360

44. Heidbuchel H et al (2015) Updated European Heart Rhythm Association practical guide on the use of non-vitamin $\mathrm{K}$ antagonist anticoagulants in patients with non-valvular atrial fibrillation. Europace 17(10):1467-1507

45. Waurick K (2016) Antikoagulanzien und Regionalanästhesie. Anästh Intensivmed 57:506-521

46. Jambor C, Spannagl M, Zwissler B (2009) Perioperative management of patients with coronary stents in non-cardiac surgery. Anaesthesist 58(10):971-985

47. Gawaz M, Geisler T (2012) Update orale Plättchenhemmer. Positionspapier der deutschen Gesellschaft fürKardiologie. Kardiologe 6:195-209

48. Windecker S et al (2015) 2014 ESC/EACTS guidelines on myocardial revascularization. Eurolntervention 10(9):1024-1094

49. Schlaghecke R et al (1992) The effect of longterm glucocorticoid therapy on pituitary-adrenal responses to exogenous corticotropin-releasing hormone. N Engl J Med 326(4):226-230

50. Fraser CG, Preuss FS, Bigford WD (1952) Adrenal atrophy and irreversible shock associated with cortisone therapy. J Am Med Assoc 149(17):1542-1543

51. Young SL, Marik P, Esposito M, Coulthard P (2009) Supplemental perioperative steroids for surgical patients with adrenal insufficiency. Cochrane Database Syst Rev 2009:CD5367 